
the detection and quantification of atmospherically relevant carbonyl compounds in aqueous medium

\author{
M. Rodigast et al. \\ Correspondence to: H. Herrmann (herrmann@ tropos.de)
}

The copyright of individual parts of the supplement might differ from the CC-BY 3.0 licence. 
2 S1.1 Chemicals and standards

3 Cyclohexanone-2,2,6,6-d4 (98\%), methacrolein (95\%), acrolein (95\%), benzaldehyde ( $\geq 99.5 \%)$, methyl vinyl 4 ketone (99\%), glyoxal (40\% in water) and 3-methylbutanone (99\%) were obtained from Sigma-Aldrich (St. Louis, 5 USA). 2,3-Butanedione (99\%) an d methyl glyoxal (40\% in water) were purchased from Fluka (St. Louis, USA). 6 Dichloromethane (Chromasolv 99,8\%) was obtained from Riedel-de Haen (St. Louis, USA) and hexane and 7 toluene as well as $o$-(2,3,4,5,6-pentafluorobenzyl)hydroxylamine hydrochloride ( $\geq 99 \%)$ were purchased from 8 Fluka (St. Louis, USA). Isooctane $(\geq 99.5 \%)$ and chloroform ( $\geq 99.8 \%)$ were obtained from Sigma-Aldrich 9 (St. Louis, USA). Hydrogen peroxide (30\% Suprapur $\left.{ }^{\circledR}\right)$ was purchased from Merck KGaA (Darmstadt, Germany). 10 Ultrapure water was used to prepare stock solutions (Milli-Q gradient A 10, 18.2 M $/ \mathrm{cm}^{2}, 3 \mathrm{ppb}$ TOC, Millipore, 11 USA).

12

\section{S2 Results}

\section{S2.1 Application of the method}

Yu et al. (1995) used the method by Cancilla et al. (1992) to quantify carbonyl compounds formed during the oxidation of isoprene. In addition Lelacheur et al. (1993) developed a PFBHA derivatisation method which was used by Yu et al. (1998) with a subsequent BSTFA (N,O-Bis(trimethylsilyl)trifluoroacetamide) derivatisation step. This method was also used by Jang and Kamens (1999) for the analysis of products originating from the oxidation of $\alpha$-pinene. Yu et al. (1997) detect carbonyl compounds formed during the oxidation of alkylbenzenes using the improved method of $\mathrm{Yu}$ et al. (1995). Carbonyl compounds were also analysed in alcohols using an optimised method by Nawrocki et al. (1996). Additionally, Fick et al. (2003) analysed products formed by the oxidation of $\alpha$-pinene with the optimised method from Yu et al. (1998). Wardencki et al. (2003) as well as Jelen et al. (2004) analysed carbonyl compounds conducted after the method from Wardencki et al. (2001). Another optimised method which is used by Cancho et al. (2002), Beránek and Kubátová (2008) and van Pinxteren and Herrmann (2013) is the EPA method 556 (Environmental Protection Agency). Furthermore Nambara et al. (1975), Sowinski et al. (2005) and Ortiz et al. (2006) detected carbonyl compounds as well but the methods were not described. 
Table S 1: Analysis of carbonyl compounds involving PFBHA derivatisation methods.

\begin{tabular}{|c|c|}
\hline Comment & Detection limits $\left[\mu \mathrm{mol} \mathrm{L^{-1 } ]}\right.$ \\
\hline $\begin{array}{l}\text { Analysis of ketosteroids } \\
\text { Synthesis of PFBHA } \\
\text { Analysis of carbonyl } \\
\text { compounds in wine }\end{array}$ & \\
\hline $\begin{array}{l}\text { Analysis of isoprene oxidation } \\
\text { products } \\
\text { Analysis of oxidation products } \\
\text { from alkylbenzenes } \\
\text { SPME for extraction of } \\
\text { carbonyl compounds }\end{array}$ & 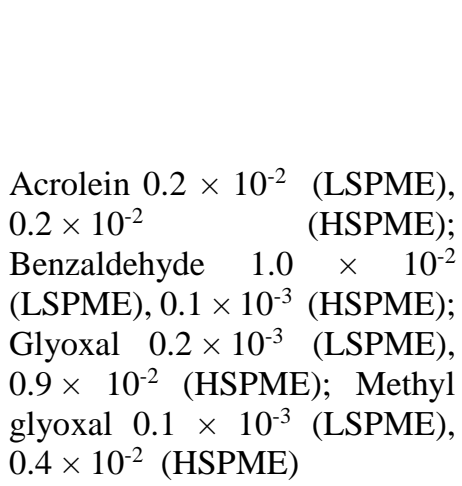 \\
\hline
\end{tabular}

Consecutively derivatisation with BSTFA

Analysis of $\alpha$-pinene oxidation products

SPME for extraction of carbonyl compounds

Derivatisation in alcohols

Methylglyoxal $0.4 \times 10^{-2}$ (HSPME)

Acrolein $3.0 \times 10^{-2} \quad$ (LLE), $0.2 \times 10^{-2}$ (SPME)

Yu et al. (1995)

Nambara et al. (1975)

Derevel and Bertrand (1993)

Yamada and Somiya (1989);

Glaze et al. (1989)

Cancilla et al. (1992)

Yu et al. (1997) Yu et al. (1995)

Bao et al. (1998)

Glaze et al. (1989);

Lelacheur et al. (1993)

Analysis of $\alpha$-pinene oxidation products in dependence of $\mathrm{OH}$ radical concentration, relative humidity and time

SPME for extraction of carbonyl compounds

SPME for extraction of $\mathrm{C}_{3}-\mathrm{C}_{10}$ aliphatic aldehydes

Headspace analysis

Analysis in spirits and vodka

Denuder-filter sampling

Analysis of bifunctional carbonyl compounds

Consecutively derivatisation with BSTFA

Solid phase microextraction of aldehydes

Glyoxal and Methylglyoxal in atlantic seawater

Glyoxal $0.1 \times 10^{-2}$ (sea water); Methyl glyoxal $0.1 \times 10^{-3}$ (sea water)
Yu et al. (1998)

Jang and Kamens (1999)

Cancho et al. (2002)

Wardencki et al. (2001)

Fick et al. (2003)

Wardencki et al. (2003)

Jelen et al. (2004)

Sowinski et al. (2005)

Ortiz et al. (2006)

Beránek and

Kubátová (2008)

Van Pinxteren and

Herrmann (2013)
Lelacheur et al. (1993);

Yu et al. (1995)

Lelacheur et al. (1993)

EPA method 556

Nawrocki et al. (1996)

Yu et al. (1998)

Wardencki et al. (2001)

Wardencki et al. (2001)

EPA method 556

EPA method 556 trimethylchlorosilane; LLE: liquid-liquid extraction; LSPME: liquid solid phase micro extraction; HSPME: headspace solid phase micro extraction 
33 Further detection limits are determined in the literature. Detection limits given by Serrano et al. (2013) cannot be compared with the data obtained in the present study as a completely different extraction technique, namely micro liquid-liquid extraction (MLLE) was used in this study. MLLE leads to much higher preconcentration depending on the sample volume that cannot be compared to the extraction technique used in the present study. Furthermore Serrano et al. (2013) used a large volume injection of $20-50 \mu \mathrm{L}$ leading to higher detection limits as well. Therefore better detection limits by a factor of 100 for benzaldehyde, 1000 for glyoxal and 10000 for methyl glyoxal were determined (Serrano et al., 2013). The detection limits determined by EPA method 556, Bao et al. (1998), Cancho et al. (2002) and Wardencki et al. (2001) are not comparable to the detection limits found in the present study as well because an electron capture detection (ECD) was used which has a better sensitivity than the detection with mass spectrometer. The better sensitivity of the ECD was also observed by Glaze et al. (1989) comparing the detection limits of the oximes measured with mass spectrometer and electron capture detection. Therefore they achieved detection limits between $0.1 \times 10^{-3}$ and $0.01 \mu \mathrm{mol} \mathrm{L}^{-1}$ for the different carbonyl compounds. In comparison the lowest detection limit determined with mass spectrometer in this study was $0.01 \mu \mathrm{mol} \mathrm{L}^{-1}$ for glyoxal and benzaldehyde. Furthermore van Pinxteren and Herrmann (2013) analysed sea water samples after a preconcentration of 100 to 200. Therefore the samples are more concentrated than in the presented study leading to lower detection limits. Seaman et al. (2006) determined detection limits with an ECD for acrolein, methacrolein, methyl vinyl ketone, glyoxal, methyl glyoxal and benzaldehyde in the gas phase and not in the aqueous phase. Thus the detection limits have been determined for gas phase measurements and are not comparable to the present method.

\section{S2.3 Extraction time}

\section{Extraction with dichloromethane}
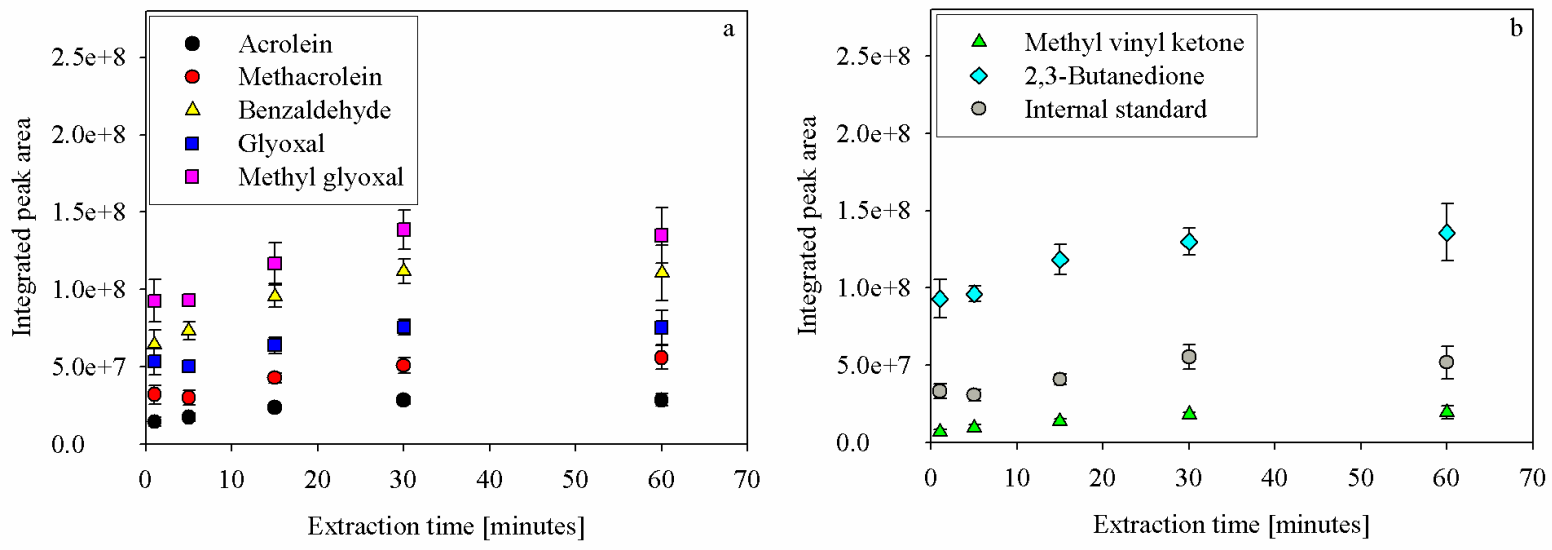

Figure S 1: Dependency of the peak area of aldehydes (a: acrolein, black; methacrolein, red; benzaldehyde, yellow; glyoxal, blue), methyl glyoxal (a, pink), ketones (b: methyl vinyl ketone, green; 2,3-butanedione, turquoise) and the internal standard (b, grey) on the extraction 
Table S 2: Extraction efficiency of the investigated carbonyl compounds.

\begin{tabular}{lccc}
\hline \multirow{2}{*}{ Carbonyl compound } & \multicolumn{3}{c}{ Extraction efficiency [\%] } \\
& 1. Extraction & 2. Extraction & 3. Extraction \\
\hline Acrolein & $97 \pm 2$ & $3 \pm 2$ & 0 \\
Methacrolein & $98 \pm 1$ & $2 \pm 1$ & 0 \\
Methyl vinyl ketone & $98 \pm 2$ & $2 \pm 2$ & 0 \\
Benzaldehyde & $98 \pm 2$ & $2 \pm 2$ & 0 \\
Glyoxal & $99 \pm 1$ & $1 \pm 1$ & 0 \\
Methyl glyoxal & $98 \pm 2$ & $2 \pm 2$ & 0 \\
2,3-Butanedione & $97 \pm 2$ & $3 \pm 2$ & 0 \\
Internal standard & $96 \pm 2$ & $4 \pm 2$ & 0 \\
\hline
\end{tabular}

57

The effect of the extraction time was also evaluated using hexane as an extraction solvent and the results are shown in Figure S 2.
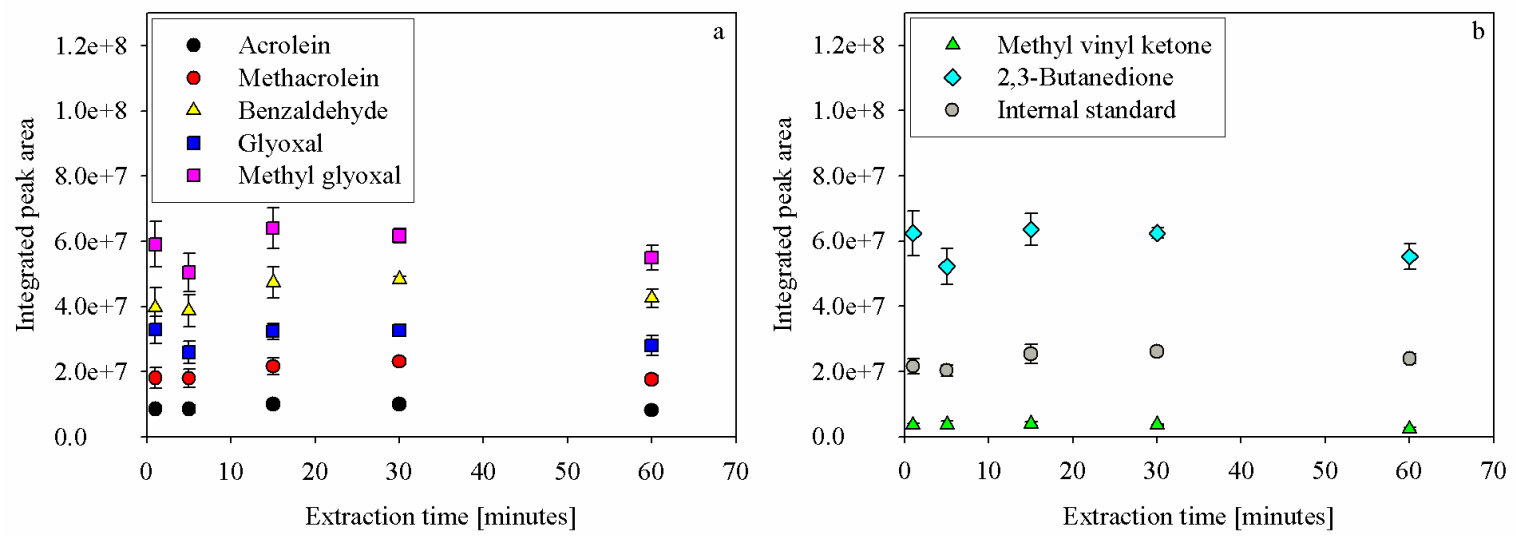

Figure S 2: Dependency of the peak area of aldehydes (a: acolein, black; methacrolein, red; benzaldehyde, yellow; glyoxal, blue), methyl glyoxal (a, pink), ketones (b: methyl vinyl ketone, green; 2,3-butanedione, turquoise) and the internal standard (b, grey) from the extraction time extracted with hexane.

64 It can be seen that hexane shows the same results as it was found for dichloromethane. After 30 minutes the 65 extraction was almost completed. Thus, it is expected that shorter extraction times cause a significant underestimation of the carbonyl compound peak areas with hexane as well. However, as hexane is the most commonly used extraction solvent an effort was made to determine correction factors for the different extraction solvents to enable assignability between the existing methods and the optimised method presented in this study. Therefore, two sets of samples were prepared. The first set was extracted using an extraction with dichloromethane for 30 minutes whereas the second set was extracted with hexane. As different extraction times can be found in the literature correction factors were determined for 1 to 60 minutes of hexane extraction (Table S 3) determined through the ratios of the peak areas extracted with hexane and dichloromethane. 
Table S 3: Correction factors for the extraction of carbonyl compounds with hexane for an extraction time between 1 and 60 minutes in relation to an extraction time of 30 minutes with dichloromethane.

\begin{tabular}{lccccc}
\hline Carbonyl compound & \multicolumn{5}{c}{ Extraction time hexane [minutes] } \\
& $\mathbf{1}$ & $\mathbf{5}$ & $\mathbf{1 5}$ & $\mathbf{3 0}$ & $\mathbf{6 0}$ \\
\hline Acrolein & $3.33 \pm 0.45$ & $3.37 \pm 0.27$ & $2.85 \pm 0.35$ & $2.82 \pm 0.22$ & $3.45 \pm 0.19$ \\
Methacrolein & $2.87 \pm 0.61$ & $2.86 \pm 0.30$ & $2.38 \pm 0.39$ & $2.21 \pm 0.28$ & $2.88 \pm 0.10$ \\
Methyl vinyl ketone & $5.36 \pm 0.87$ & $5.34 \pm 1.66$ & $4.74 \pm 0.74$ & $5.06 \pm 0.58$ & $7.86 \pm 1.05$ \\
Benzaldehyde & $2.88 \pm 0.63$ & $2.91 \pm 0.18$ & $2.37 \pm 0.30$ & $2.31 \pm 0.15$ & $2.63 \pm 0.09$ \\
Glyoxal & $2.32 \pm 0.30$ & $2.94 \pm 0.32$ & $2.34 \pm 0.21$ & $2.31 \pm 0.18$ & $2.72 \pm 0.31$ \\
Methyl glyoxal & $2.37 \pm 0.35$ & $2.76 \pm 0.18$ & $2.17 \pm 0.23$ & $2.25 \pm 0.24$ & $2.52 \pm 0.19$ \\
2,3-Butanedione & $2.10 \pm 0.30$ & $2.50 \pm 0.15$ & $2.06 \pm 0.23$ & $2.09 \pm 0.19$ & $2.36 \pm 0.12$ \\
Internal standard & $2.59 \pm 0.58$ & $2.71 \pm 0.17$ & $2.22 \pm 0.50$ & $2.12 \pm 0.34$ & $2.31 \pm 0.20$ \\
\hline
\end{tabular}

The strongest dependency towards the extraction solvent was found for methyl vinyl ketone (7.86 \pm 1.05$)$ and weakest for 2,3-butanedione $(2.06 \pm 0.23)$. With the obtained correction factors an underestimation of the carbonyl compound concentration caused by a less effective extraction with hexane can be corrected.

\section{S2.4 Derivatisation time}
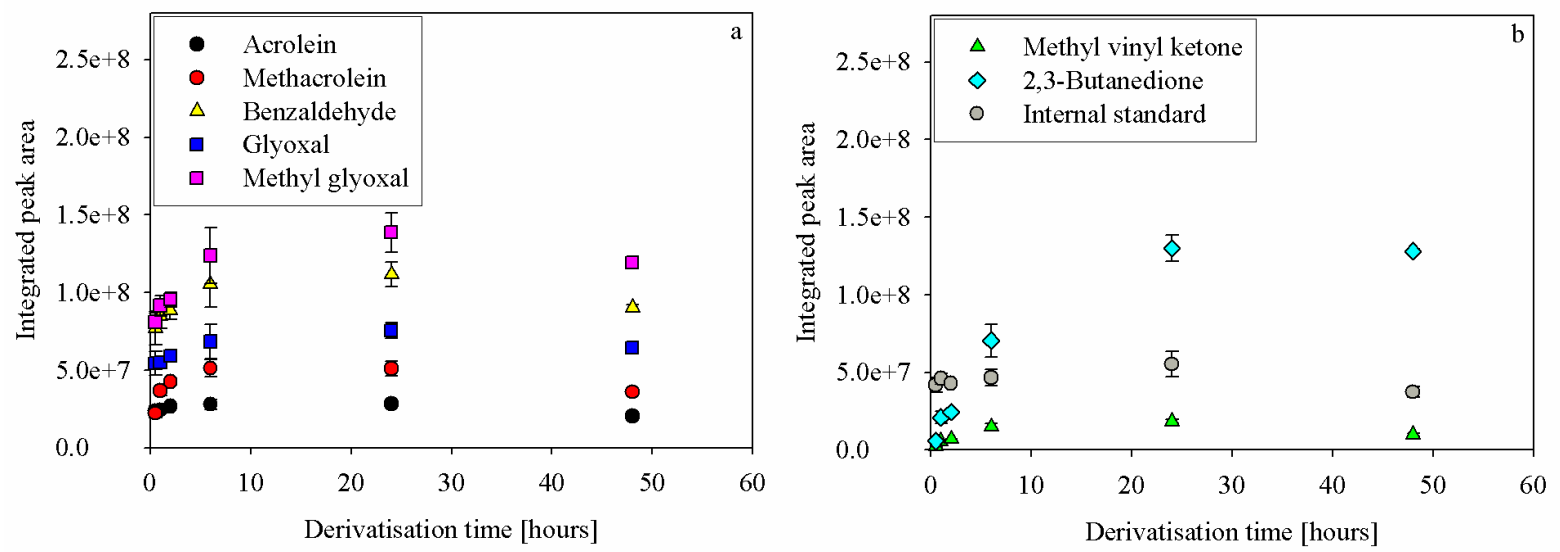

Figure S 3: Influence of the derivatisation time on the integrated peak area of aldehydes (a: acrolein, black; methacrolein, red; benzaldehyde, yellow; glyoxal, blue), methyl glyoxal (a, pink), ketones (b: methyl vinyl ketone, green; 2,3-butanedione, turquoise) and the internal standard (b, grey). 

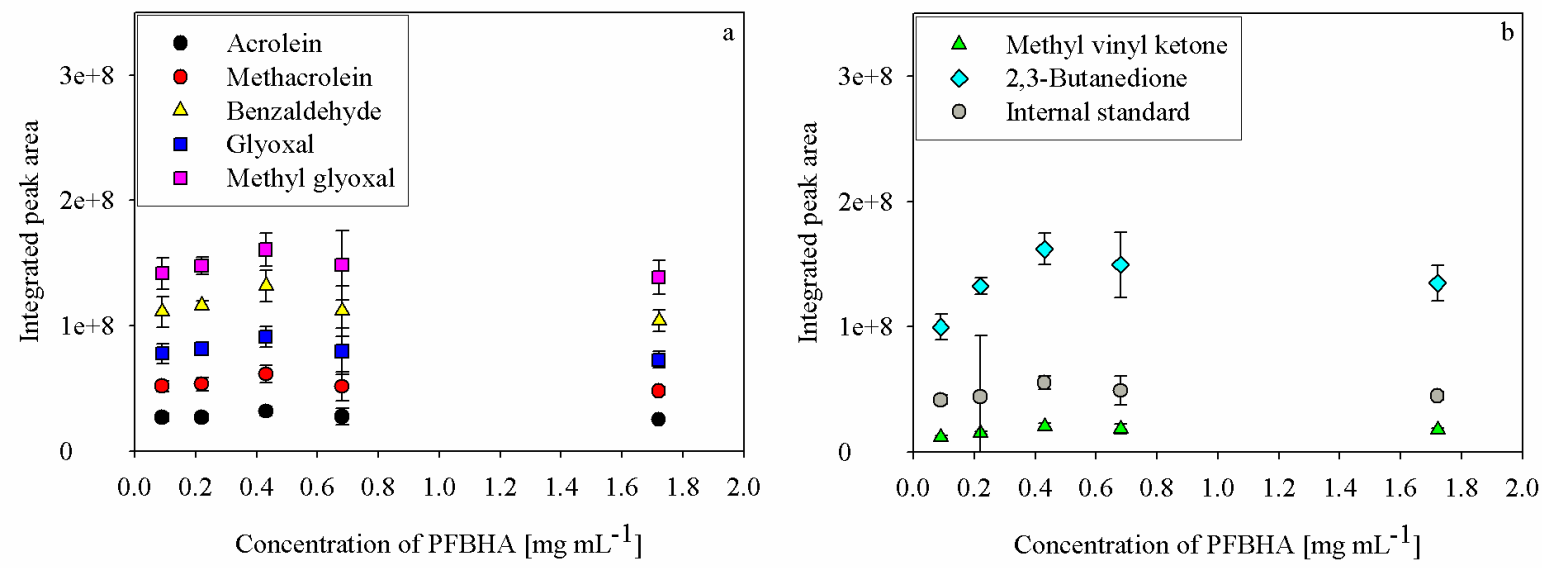

Figure S 4: Dependency of the integrated peak area of investigated aldehydes (a: acrolein, black; methacrolein, red; benzaldehyde, yellow; glyoxal, blue), methyl glyoxal (a, pink) and ketones (b: methyl vinyl ketone, green; 2,3-butanedione, turquoise) as a function of PFBHA concentration in the sample solution. Please note, the internal standard is given in grey (b).

\section{S2.6 pH value during derivatisation and extraction}
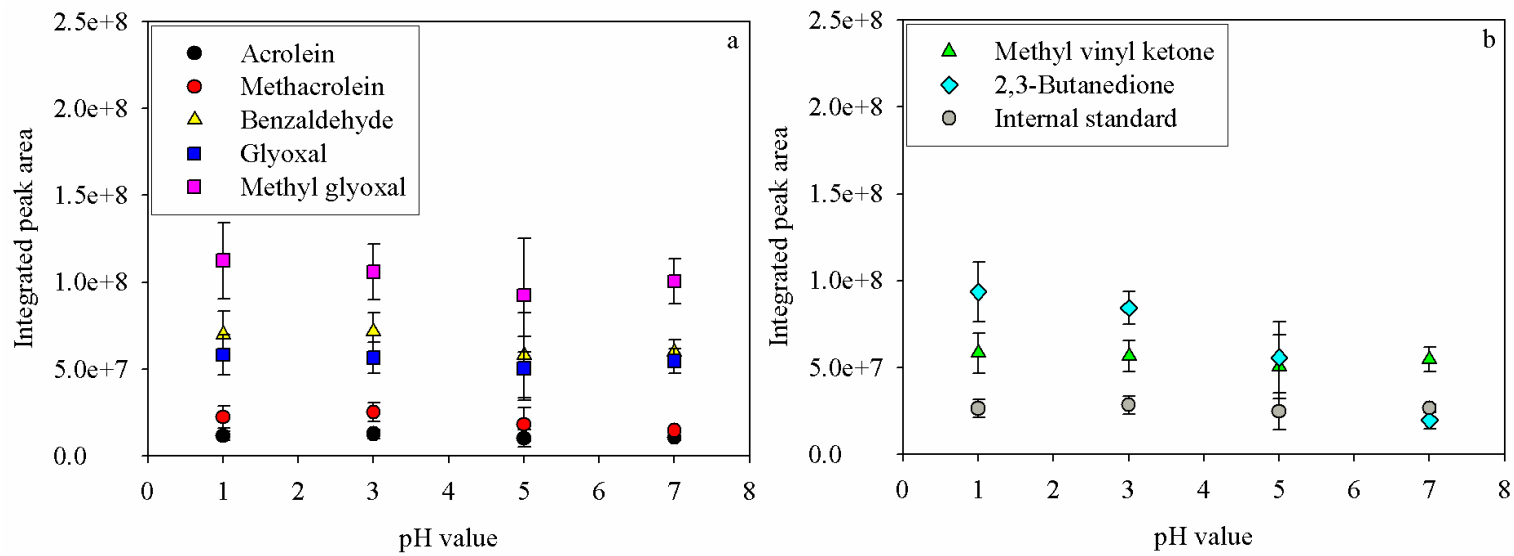

Figure S 5: Influence of the $\mathrm{pH}$ value on the derivatisation reaction of aldehydes (a: acrolein, black; methacrolein, red; benzaldehyde, yellow; glyoxal, blue), methyl glyoxal (a, pink), ketones (b: methyl vinyl ketone, green; 2,3-butanedione, turquoise) and the internal standard (b, grey).
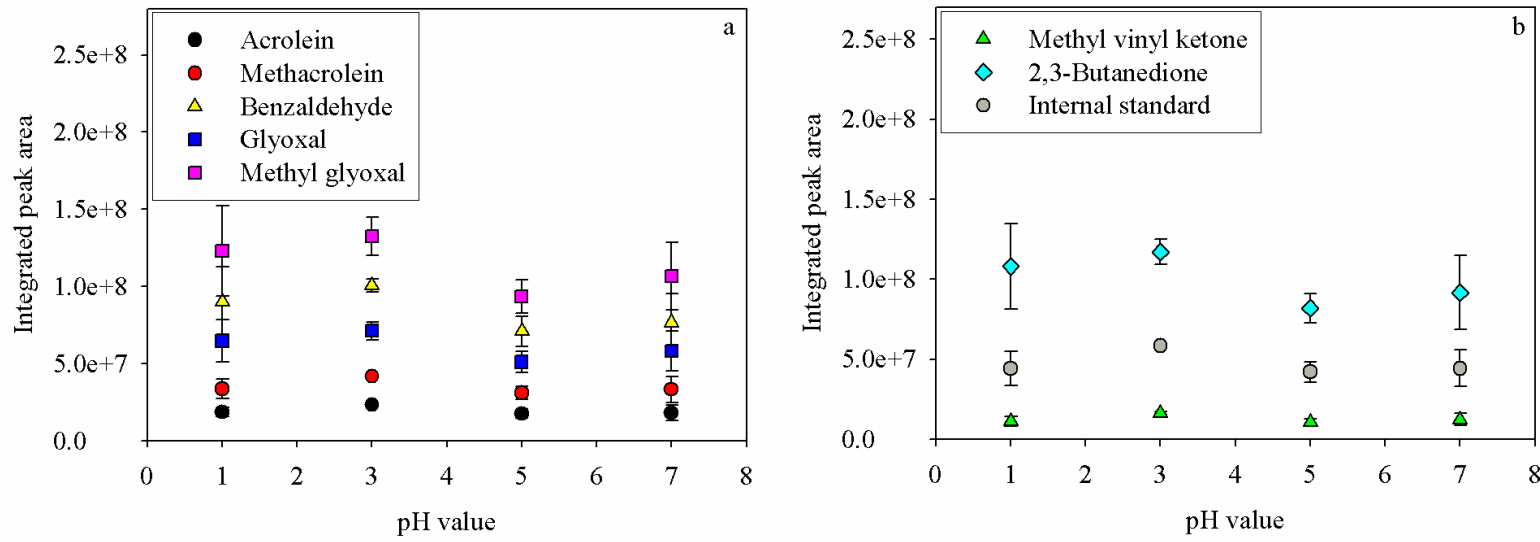

Figure S 6: Influence of the pH value on the extraction efficiency of aldehydes (a: acrolein, black; methacrolein, red; benzaldehyde, yellow; glyoxal, blue), methyl glyoxal (a, pink), ketones (b: methyl vinyl ketone, green; 2,3-butanedione, turquoise) and the internal standard (b, grey) 


\section{S2.7 Proof of principle}

The optimised method (dichloromethane as extraction solvent, 30 minutes extraction time, $24 \mathrm{~h}$ derivatisation time, $0.43 \mathrm{mg} \mathrm{mL}^{-1}$ PFBHA, $\mathrm{pH}=3$ for the derivatisation and $\mathrm{pH}=1$ for the extraction) was applied to a series of stock solutions. The concentrations of the seven target carbonyl compounds were varied in a range of 2 to $16 \mu \mathrm{mol} \mathrm{L}^{-1}$ (Figure S 7, supplementary material S 2.7). From the repetitive analysis of the dilution series a $\mathrm{R}^{2}$ of 0.99 and detection limits between 0.01 and $0.17 \mu \mathrm{mol} \mathrm{L}^{-1}$ were achieved (Table 3).

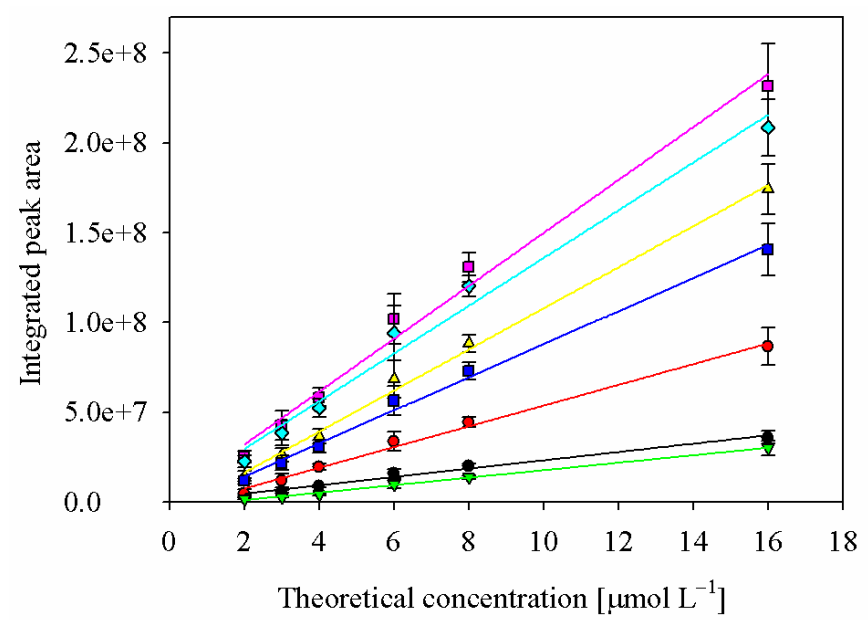

Figure $S$ 7: Calibration curve for acrolein (black, $\mathrm{R}^{2}=0.987$ ), methacrolein (red, $\mathrm{R}^{2}=0.993$ ), methyl vinyl ketone (green, $\mathrm{R}^{2}=0.997$ ), benzaldehyde (yellow, $\mathrm{R}^{2}=0.996$ ), glyoxal (blue, $\mathrm{R}^{2}=0.995$ ), methyl glyoxal (pink, $\mathrm{R}^{2}=0.984$ ) and 2,3-butanedione (turquoise, $\mathrm{R}^{2}=0.984$ ) in the concentration range of 2 to $16 \mu \mathrm{mol} \mathrm{L^{-1 }}$.

\section{References}

Bao, M. L., Pantani, F., Griffini, O., Burrini, D., Santianni, D., and Barbieri, K.: Determination of carbonyl compounds in water by derivatization - solid-phase microextraction and gas chromatographic analysis, J. Chromatogr. A, 809, 75-87, 1998.

Beranek, J. and Kubatova, A.: Evaluation of solid-phase microextraction methods for determination of trace concentration aldehydes in aqueous solution, J. Chromatogr. A, 1209, 44-54, 2008.

Cancilla, D. A., Chou, C. C., Barthel, R., and Hee, S. S. Q.: Characterisation of the O-(2,3,4,5,6pentafluorobenzyl)-hydroxylamine hydrochloride (PFBOA) derivatives of some aliphatic monoaldehydes and dialdehydes and quantitative water analysis of these aldehydes, J. AOAC Int., 75, 842-854, 1992.

Derevel, G. and Bertrand, A.: A method for the detection of cabonyl-compounds in wine - glyoxal and methylglyoxal, Journal of the Science of Food and Agriculture, 61, 267-272, 1993.

Fick, J., Pommer, L., Nilsson, C., and Andersson, B.: Effect of $\mathrm{OH}$ radicals, relative humidity, and time on the composition of the products formed in the ozonolysis of alpha-pinene, Atmospheric Environment, 37, 4087 4096, 2003.

Jang, M. and Kamens, R. M.: Newly characterized products and composition of secondary aerosols from the reaction of alpha-pinene with ozone, Atmospheric Environment, 33, 459-474, 1999. 
Jelen, H. H., Dabrowska, A., Klensporf, D., Nawrocki, J., and Wasowicz, E.: Determination of C3-C10 aliphatic aldehydes using PFBHA derivatization and solid phase microextraction (SPME). Application to the analysis of beer, Chem. Anal., 49, 869-880, 2004.

Nambara, T., Kigasawa, K., Iwata, T., and Ibuki, M.: Studies on steroids . 103. new type of derivative for electron capture gas chromatography of ketosteroids, Journal of Chromatography, 114, 81-86, 1975.

Ortiz, R., Hagino, H., Sekiguchi, K., Wang, Q. Y., and Sakamoto, K.: Ambient air measurements of six bifunctional carbonyls in a suburban area, Atmos. Res., 82, 709-718, 2006.

Sowinski, P., Wardencki, W., and Partyka, M.: Development and evaluation of headspace gas chromatography method for the analysis of carbonyl compounds in spirits and vodkas, Anal. Chim. Acta, 539, 17-22, 2005.

van Pinxteren M, Herrmann H.: Glyoxal and methylglyoxal in Atlantic seawater and marine aerosol particles: method development and first application during the Polarstern cruise ANT XXVII/4, Atmos. Chem. Phys., 13, 11791-11802, 2013.

Wardencki, W., Orlita, J., and Namiesnik, J.: Comparison of extraction techniques for gas chromatographic determination of volatile carhonyl compounds in alcohols, Fresenius J. Anal. Chem., 369, 661-665, 2001.

Wardencki, W., Sowinski, P., and Curylo, J.: Evaluation of headspace solid-phase microextraction for the analysis of volatile carbonyl compounds in spirits and alcoholic beverages, J. Chromatogr. A, 984, 89-96, 2003. WATER BY THE PFBOA METHOD, Ozone-Science \& Engineering, 11, 127-141, 1989.

$\mathrm{Yu}$, J. Z., Flagan, R. C., and Seinfeld, J. H.: Identification of products containing - $\mathrm{COOH},-\mathrm{OH}$, and $-\mathrm{C}=\mathrm{O}$ in atmospheric oxidation of hydrocarbons, Environmental Science \& Technology, 32, 2357-2370, 1998.

Yu, J. Z., Jeffries, H. E., and Sexton, K. G.: Atmospheric photooxidation of alkylbenzenes .1. Carbonyl product analyses, Atmospheric Environment, 31, 2261-2280, 1997. 